
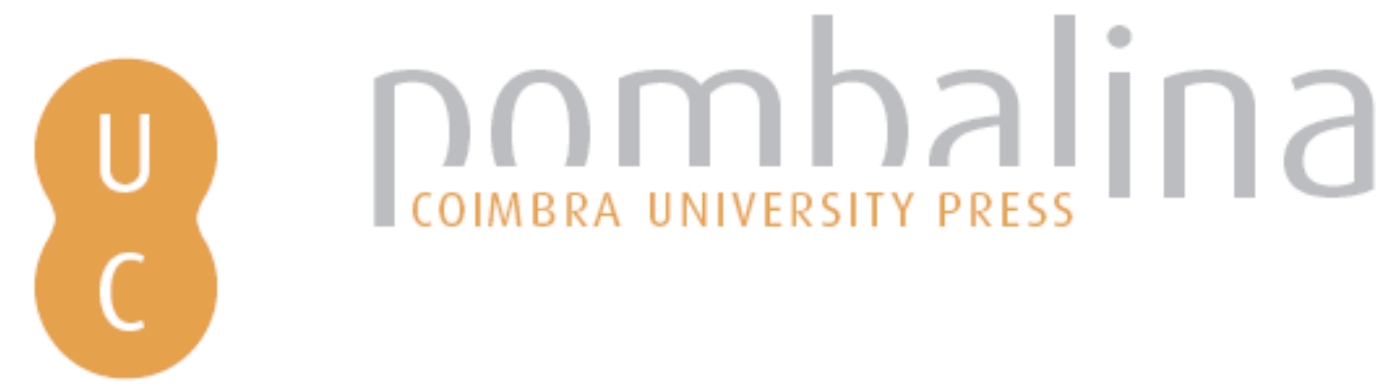

\title{
Campanhas de educação de adultos no Brasil, em Portugal e no Rio Grande Do Norte e os seus princípios educativos (Século XX)
}
Autor(es):
Araújo, Marta Maria de; Alcoforado, Luís
Publicado por: Imprensa da Universidade de Coimbra
URL
persistente:
URI:http://hdl.handle.net/10316.2/41320
DOI:
DOI:https://doi.org/10.14195/978 98926 1326-0_31
Accessed : $\quad$ 26-Apr-2023 15:31:27

A navegação consulta e descarregamento dos títulos inseridos nas Bibliotecas Digitais UC Digitalis, UC Pombalina e UC Impactum, pressupõem a aceitação plena e sem reservas dos Termos e Condições de Uso destas Bibliotecas Digitais, disponíveis em https://digitalis.uc.pt/pt-pt/termos.

Conforme exposto nos referidos Termos e Condições de Uso, o descarregamento de títulos de acesso restrito requer uma licença válida de autorização devendo o utilizador aceder ao(s) documento(s) a partir de um endereço de IP da instituição detentora da supramencionada licença.

Ao utilizador é apenas permitido o descarregamento para uso pessoal, pelo que o emprego do(s) título(s) descarregado(s) para outro fim, designadamente comercial, carece de autorização do respetivo autor ou editor da obra.

Na medida em que todas as obras da UC Digitalis se encontram protegidas pelo Código do Direito de Autor e Direitos Conexos e demais legislação aplicável, toda a cópia, parcial ou total, deste documento, nos casos em que é legalmente admitida, deverá conter ou fazer-se acompanhar por este aviso.

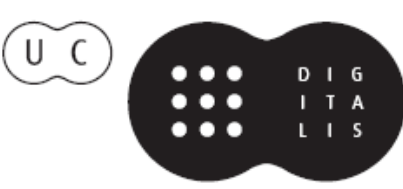




\title{
31. CAMPANHAS DE EDUCAÇÃO DE ADULTOS NOBRASIL, EM PORTUGAL E NO RIOGRANDE DO NORTE E OS SEUS PRINCÍPIOS EDUCATIVOS ( S ÉCULO XX)
}

Marta Maria de Araújo 152

Luís Alcoforado 153

\begin{abstract}
Resumo
O texto realiza uma abordagem histórica de campanhas de educação de jovens e adultos oficializados no século XX em Portugal e no Brasil e, em particular, no estado do Rio Grande do Norte. Em análise, são relidas as experiências promovidas pela Campanha Nacional de Educação de Adultos (1952-1956), em Portugal, pela Campanha de Educação de Adultos com base no Plano de Ensino Supletivo (1947-1963), no Brasil, e as "40 horas" de Angicos, no estado do Rio Grande do Norte - Brasil. Com base em um corpus constituído de entrevista, censos populacionais, legislação educacional e relatos, as referidas experiências são analisadas à luz dos seus fundamentos pedagógicos e dos condicionamentos econômicos, culturais, sociais e políticos que as enformaram. Nesse âmbito, são
\end{abstract}

152 Universidade Federal do Rio Grande do Norte, Brasil.

153 Universidade de Coimbra, Portugal. 
destacadas ideias de Paulo Freire que dialogaram criticamente com fundamentos pedagógicos vigentes, particularmente aqueles que atribuíam ao povo papéis passivos no processo de alfabetização. Ainda nesse âmbito, o texto ressalta o papel de Freire na construção de uma perspectiva que torna o alfabetizando sujeito do seu processo educativo, singularizando a função conscientizadora e transformadora da alfabetização.

\section{Abstract}

This text presents a historical approach to youth and adult education campaigns made official in the twentieth century in Portugal and Brazil, and particularly in Rio Grande do Norte state. In focus are the experiences promoted by the Campanha Nacional de Educação de Adultos (National Campaign of Adult Education) (1952-1956), in Portugal, by the Campanha de Educação de Adultos (Campaign of Adult Education), based on the Plano de Ensino Supletivo (Supplementary Plan of Education) (1947-1963), in Brazil, and by the "40 hours" of Angicos, in Rio Grande do Norte - Brazil. Taking into account a corpus of interviews, population registers, educational legislation and reports, such experiences are analyzed in the light of their pedagogical principles and of the economic, cultural, social and political constraints that shaped them. In this context, the discussion emphasizes Paulo Freire's ideas that critically dialogued with existing educational principles, mainly those which attributed to people passive roles in the literacy process. Still in this scope, the paper highlight Freire's role in the construction of a view that frame the students as subjects of their own process of learning, drawing attention to the conscientizing and transforming function of literacy. 
A Campanha de Educação de Adultos oficializada no Brasil no período de dezesseis anos (1947-1963) com base no Plano de Ensino Supletivo, a Campanha Nacional de Educação de Adultos em Portugal no período de quatro anos (1952-1956) conforme o Plano de Educação Popular e a Campanha de Alfabetização de Adultos ou a Experiência das "40 horas" de Angicos (Rio Grande do Norte) segundo um Projeto de Educação de Adultos no período de três meses (18 de janeiro a 2 de abril de 1963) trazem subtendidos, em suas histórias, os condicionamentos econômicos, culturais, sociais, políticos que lhes promoveram, bem como os fundamentos pedagógicos da práxis educacional.

Com base no corpus documental (entrevista, censos populacionais, legislação educacional, relatos), o trabalho histórico pertinente à Campanha de Educação de Jovens e Adultos no Brasil, em Portugal e no Rio Grande do Norte tem o objetivo de depreender, das ideias pedagógicas de seus concebedores, o entendimento de educação e de educação de adultos, os quais lhes destinavam a exercitar na práxis educacional. Teorizar acerca da educação do jovem e do adulto, em meados do século XX consistia, pois, refletir sobre o adulto e o jovem ajustado ou integrado à sociedade industrial. Subjacente à acepção de sociedade industrial, havia, pois, uma variedade de desafios que não se esgotava - como bem traduz Paulo Freire (1980, p. 40) num tipo padronizado de resposta. "Nas relações que o homem estabelece com o mundo há, por isso mesmo, uma pluralidade na própria singularidade."

\section{A Campanha de Educação de Adultos no Brasil}

No Brasil no governo do General Eurico Gaspar Dutra (1946-1951) e na gestão do Ministro da Educação e Saúde, Clemente Mariani Bittencourt (1946-1950), foi levada a efeito a Campanha de 
Educação de Adolescentes e Adultos ou, abreviadamente, Campanha de Educação de Adultos.

O Ministro Clemente Mariani Bittencourt nomeou, em $1^{\circ}$ de fevereiro de 1947, o Diretor-Geral do Departamento Nacional de Educação, Manoel Bergström Lourenço Filho para coordenador do Plano Geral de Ensino Supletivo sob a denominação de Campanha de Educação de Adolescentes e Adultos Analfabetos ou "funcionalmente analfabetos".

Em 15 de janeiro de 1947, o Ministro Clemente Mariani Bittencourt, em entrevista para Imprensa escrita, esclareceu algumas das medidas preparatórias do governo federal em proveito da educação popular mediante a Campanha de Educação de Adolescentes e Adultos.

Em primeiro lugar, todas as providências serão tomadas para abertura, em cidades, vilas e povoados, de nada menos de dez mil classes de ensino supletivo, para adolescentes e adultos analfabetos. [...] Essas classes, que entrarão a funcionar a 15 de abril [1947], mediante acordo com os Estados, Territórios e Distrito Federal, aproveitando instalações e professorado existentes, na maioria das localidades. Mas, onde for necessário, improvisam-se instalações, e os docentes necessários serão designados. (Serviço Gráfico do Instituto Brasileiro de Geografia e Estatística, 1947, p. 3)

Ainda que houvesse as políticas de educação escolar primária para adultos nos Estados e Territórios e Distrito Federal (2.077 cursos e 164.487 alunos matriculados aproximadamente), o Censo Populacional de 1940 havia mostrado que 55\% (13.279.919, aproximadamente) do grupo de população adolescente e adulta encontrava-se na condição de analfabetos com variações regionais acentuadas. A elevada taxa de analfabetismo na população ativa de todo país - segundo Lourenço Filho (1950, p. 74, grifo nosso) - "[...] estava a exigir remédio, já pelo que pudesse representar, de modo 
direto, para a vida cívica e econômica do país, já, e, também, no que pudesse influir para alertar a consciência pública em matéria de educação popular."

Os cursos de ensino primário supletivo $\left(1^{\mathrm{a}}, 2^{\mathrm{a}}\right.$ e $3^{\mathrm{a}}$ séries $)$ receberam materiais e recursos didáticos (cartilhas, folhetos, cartazes, quadros murais, boletins); turnos dos cursos (turno de adolescentes e turnos de adultos), horário de funcionamento das classes (tarde e noite), tempo das aulas (duas horas, no mínimo), período escolar (abril a novembro), orientação educativa da Campanha (Ler para Saber, Saber para Viver mais plenamente, ou melhor).

O educador Manoel Bergström Lourenço Filho, signatário do Manifesto dos Pioneiros da Educação Nova (1932), intelectual idôneo e técnico da educação de projeção nacional e internacional - segundo as suas estudiosas Gandini e Riscal (2002, p. 753-754, grifo das autoras), - "[...] foi o grande sistematizador da teoria educacional de um longo período de nossa história, fornecendo rigorosa elaboração de conceitos [...], dando forma ao aparelho do Estado no setor da Educação e, ao mesmo tempo, construindo o referencial teórico e doutrinário para as atividades educacionais."

As teorizações do educador escolanovista Manoel Bergström Lourenço Filho - concebedor e coordenador do campanha do extensão do ensino supletivo por todo o país quando foi Diretor do Instituto Nacional de Estudos Pedagógicos (1938-1946), da Campanha de Educação de Adultos (1947-1951) e do primeiro Plano de Educação Popular de iniciativa do governo federal - tornar-se-iam referências para sistematizar e expandir as políticas institucionais de educação escolar, em geral, de educação de jovens e adultos, em particular, em suas interdependências com a organização e a vida coletiva nacionais (em seus aspectos econômico, social e político), que se deve servir. Enquanto processo social inelutável, a educação tornou-se deferida pelos Estados que planeja e exerce de modo preponderante. 
Descobrem-se 'relações de dependência' entre aspectos bem definidos do processo educativo e o tipo de economia, a organização familiar, a estrutura religiosa, as condições político-sociais, as de ordem e segurança, os próprios recursos de comunicação e transportes - tudo quanto possa concorrer para a agregação dos homens ao redor de ideais e de técnicas, que sirvam à continuidade e ao aperfeiçoamento das formas de vida coletiva. (Lourenço Filho, 2002 [1940], p. 12)

As teorizações sobre a educação escolar de viés sociológico de Lourenço Filho envoltas de uma singular concepção de História, de vida coletiva em mudança, além de reforma do homem por uma educação escolar reformada e extensiva para todos, certamente proporcionariam conceituar e sistematizar um "plano estatuto" de educação de jovens e adultos não alfabetizados na idade própria em face dos mais graves e complexos problemas da ordem social.

Em artigo publicado na Revista Brasileira de Estudos Pedagógicos de título "O problema da educação de adultos", Lourenço Filho (1945, p. 170 e 173) entendia a educação de adultos como uma medida supletiva de organização social e de combate do analfabetismo. "Será por interesse coletivo e por sentimento de cooperação social [...]" que convinha disseminar o ensino supletivo. Quer pelo aspecto supletivo e quer pelo aspecto profissional, a educação de adultos surgia "[...] como esforço no sentido de equilíbrio e reajustamento do indivíduo ao seu ambiente social." Organizar e expandir a educação de adultos pelas teorizações de Lourenço Filho (1945, p. 185) era um imperativo político do Estado, "[...] obra de organização social, de revigoramento econômico e fundamentação democrática, necessária e urgente."

No terceiro ano da Campanha de Educação de Adultos (1949) num curso de orientação pedagógica para os professores dos cursos primários supletivos promovido pela Fundação Getúlio Vargas em colaboração com o Ministério da Educação e Saúde, Lourenço Filho 
(1949, p. 123) conceituava a "educação de adultos" de nível primário e supletivo como aquela que "[...] atende a alguma coisa 'que falta' e 'que deva ser suprida', para maior benefício individual e social." Por educação de nível primário e supletivo para adultos por meio da Campanha de Educação de Adultos - segundo Lourenço Filho (1949, p. 124) recupera-se "[...] grandes massas de nossa população, que vivem como que 'à margem' dos mais sérios problemas da vida nacional." O analfabetismo de homens e mulheres à margem dos progressos sociais, a educação de adultos, antes de tudo, era para que,

[...] melhor possa ajustar-se à vida social e às preocupações de bem-estar e de progresso social. E devemos educá-los porque essa obra é de defesa nacional, porque concorrerá para que todos melhor saibam defender a saúde, trabalhar mais eficientemente, viver melhor no seu próprio lar, na sociedade, em geral. Devemos educa-los porque a própria Constituição da República estabelece que 'a educação é direito de todos'. (Lourenço Filho, 1949, p. 125)

Ademais, a educação de jovens e adultos analfabetos interagia com o contexto coletivo que transcendia para o grupo familiar e o futuro de todas as crianças do Brasil. Por essa especificação política e social, Lourenço Filho (1949, p. 125) teorizava: "Educar os adultos é, assim, salvar a própria vida das crianças.” Para esse educador, isso sucedia quando os pais eram analfabetos, em geral, não podiam compreender seus próprios filhos ainda crianças. Nos lares de famílias analfabetas pouco ou nada era o estímulo da criança à cultura letrada, e, assim, tendiam a ser reabsorvidas pelo analfabetismo ambiente. Por tudo isso, "[...] é que podemos dizer, sem medo de errar, que, ainda por amor às crianças, é que devemos educar adolescentes e adultos." Educar a criança, o jovem e o adulto exprimia, acima de tudo, a preocupação da solidariedade da obra educativa em todas as idades da vida. 


\section{A Campanha Nacional de Educação de Adultos em Portugal}

Em Portugal no regime do Estado Novo em Portugal (1933-1974), notadamente na presidência de António de Oliveira Salazar no Conselho de Ministros (1933-1968) foi desenvolvida a Campanha Nacional de Educação de Adultos destinada, predominantemente, a grupos de jovens e adultos com idade entre 14 a 35 anos que não haviam frequentado a escola ou tinham abandonado precocemente. O censo da população de 1940 evidenciou uma elevada percentagem de uma população de jovens e adultos analfabetos entre 14 e 35 anos de idade, atingindo quase dois milhões em 1951.

A escolaridade primária obrigatória como antídoto do analfabetismo relativo aos jovens e adultos levaria as autoridades do Ministério da Educação Nacional a promulgar, no âmbito do Plano de Educação Popular, a Campanha Nacional de Educação de Adultos, a cargo da Direção-Geral do Ensino Primário do Ministério da Educação, elaborado, coordenado e dinamizado pelo Subsecretário de Estado da Educação Nacional, Dr. Henrique Veiga de Macedo (1949-1955), e o Ministro Fernando Andrade Pires de Lima (1947-1955).

Nos Cursos de Educação de Adultos (diurnos e noturnos) - destinados à preparação e aprovação de alunos jovens e adultos no exame na $3^{a}$ classe do ensino primário (escolaridade obrigatória) - o programa mínimo de estudos (basicamente o programa do ensino primário elementar) compreendia rudimentos da leitura, da escrita e do cálculo aritmético, com acréscimo das noções básicas de educação moral e cívica; higiene e defesa da saúde; agricultura e pecuária; organização corporativa, previdência social, segurança no trabalho (Decreto-Lei n. ${ }^{\circ} 38.969$, de 27 de outubro de 1952).

Para uma esclarecida política nacional de combate ao analfabetismo, em seus múltiplos aspectos de ordem histórica, geográfica, 
social e econômica, demandaria, portanto, uma definição de homens e mulheres adultos analfabetos e uma definição de educação de jovens e adultos analfabetos.

O analfabeto não tem a noção da vantagem do ensino e entende, na sua visão deformada das coisas, que os filhos não carecem, para as lutas da vida, de quaisquer habilitações literárias. Essa triste realidade torna ainda mais premente a necessidade de fazer alguma coisa para educar os analfabetos, os quais irão, por experiência vivida, convencendo-se do interesse prático de instruir os filhos. Será esta, assim, mais uma maneira de ativar a frequência da escola primária. (Decreto-Lei ${ }^{\circ}{ }^{\circ} 38.969$, de 27 de outubro de 1952, p. 1080)

Nesse fragmento, percebe-se uma simetria entre as ideias pedagógicas de Henrique Veiga de Macedo com as de Lourenço Filho. Nas comemorações do primeiro ano da Campanha Nacional de Educação de Adultos de Portugal (15 de novembro de 1953), Dr. Henrique Veiga de Macedo reforçava aquela definição de homens e mulheres adultos analfabetos, refletindo sobre as razões da persistência dessa situação.

[...] Pela própria natureza das causas do analfabetismo entre nós, e em especial do facto de, mormente, nos meios rurais, o nosso povo, pelas condições de vida, pelo regime do seu trabalho e até pela força do hábito e da rotina, não sentia a necessidade de aprender. (Macedo, 1953 apud Ferreira \& Mota, 2011, p. 182)

Uma das ideias pedagógicas da educação primária de jovens e adultos - mediante o Decreto-Lei n. ${ }^{\circ} 38.969$, de 27 de outubro de 1952 , p. 1080 - corresponderia em ensinar o analfabeto "[...] a aperfeiçoar o seu trabalho e as suas técnicas de técnicas de produção 
[...], ajudá-lo a tomar consciência dos valores sociais, econômicos, estéticos, cívicos, morais e espirituais [...]," para, assim, adaptá-lo às condições da vida moderna coletiva.

\section{A Campanha de Alfabetização de Adultos no Rio Grande do Norte}

No Rio Grande do Norte no governo de Aluízio Alves (1961-1966) e na gestão do Secretário de Educação e Cultura Calazans Fernandes, foi desenvolvida na cidade de Angicos (cidade natal do governador), conforme o próprio Secretário Calazans Fernandes e Antonia Terra (1994, p. 52) com a concordância de Paulo Freire a "[...] Campanha de Alfabetização [de Adultos] patrocinada pela Aliança para o Progresso, da qual resultou a Experiência das "40 horas" de Angicos."

No Rio Grande do Norte, a população estimada pelo Censo Demográfico de 1960 foi de 1.140 .823 habitantes nos seus oitenta e três municípios; 427.243 residiam em área urbana e 585.515 em área rural, com índices altos de analfabetismo e semi-analfabetismo. Por sua vez, a quantidade de mulheres e homens no grupo entre 15 e 44 anos de idade que diziam não saber ler e escrever era de 117.754 mulheres (moradoras em área urbana 33.988 e em área rural 83.766) e de 117.441 homens (moradores em área urbana 26.568 e em área rural 90.873). Pelo trabalho de Fernandes e Terra (1994), a população estimada no município de Angicos era de, aproximadamente, 9.542 habitantes, sendo $75 \%$ de homens e mulheres analfabetos de mais de quatorze anos.

A Campanha de Alfabetização de Adultos ou como foi conhecida e reconhecida - a Experiência das " 40 horas" de Angicos - oficialmente foi inaugurada no dia 18 de janeiro de 1963, com a $1^{\text {a }}$ Aula do educador Paulo Freire, assistida pelo governador do Estado 
Aluízio Alves, pelo Secretário de Educação e Cultura Calazans Fernandes, pelos quinze estudantes universitários que implantaram e efetuaram as " 40 horas", pelos jovens e adultos para alfabetização (aproximadamente 299 alunos; 143 mulheres e 156 homens), além de autoridades convidadas e jornalistas.

A conclusão da primeira turma da Experiência de " 40 horas" de Angicos se deu em 2 de abril desse ano de 1963, com a cerimônia de entrega de trezentos certificados aos jovens e adultos alfabetizados de 20 a 71 anos de idades na presença do presidente da República, João Belchior Marques Goulart (1961-1964), ministrante da $40^{a}$ Aula da Experiência das "40 horas" de Angicos, além do Ministros de Estado, governadores de Estados do Nordeste, representantes da Aliança para o Progresso, Diretor da Superintendência do Desenvolvimento do Nordeste (Sudene).

A Experiência das " 40 horas" de Angicos tornar-se-ia a "experiência clássica" do chamado "Método Paulo Freire", dirigido pelo próprio Paulo Freire. Nas palavras de Fernandes e Terra (1994, p. 147), o município de Angicos foi "[...] onde se desenrolou o primeiro programa piloto de alfabetização de adultos, pelo método Paulo Freire de 40 horas [...]" com o uso de materiais audiovisuais.

O Brasil vivia então - teoriza Paulo Freire (1980, p. 46) - exatamente o trânsito de uma época que se esvaziava para outra época que se consubstanciava com prospectiva de uma nova plenitude. "Nutrindo-se de mudanças, o tempo de trânsito é mais do que simples mudança. Ele implica realmente nesta marcha acelerada que faz a sociedade à procura de novos temas e de novas tarefas."

No dinamismo complexo dessa época de trânsito de superação de antigos temas, emerge uma percepção renovada de muitos deles - por conseguinte para Freire (1980, p. 59) - a educação democrática do povo para o exercício da democracia e para a responsabilidade social, econômica e política "[...] haveria de ser corajosa, propondo ao povo a reflexão sobre si mesmo, sobre seu 
tempo, sobre suas responsabilidades, sobre seu papel no novo clima cultural da época de transição".

A educação de adultos de "método" dialogal e ativo seria consequência do aprendizado ligado às condições recentes da atualidade e, ainda, capaz de cooperar com o povo se alfabetizando "[...] na indispensável organização reflexiva de seu pensamento". Sublinha Freire (1980, p. 106), a própria essência da democracia, envolve um atributo fundamental que lhe é intrínseca - a mudança constante.

Assumir em Angicos a alfabetização de jovens e adultos mediante um método dialogal, ativo, participante e crítico seria admitir o discernimento de um Projeto de Educação de Adultos em bases populares, com o povo e para o povo em sua e com sua realidade, numa sociedade em transição com suas intensas contradições. A materialização de um programa mínimo de aprendizado de leitura e escrita (uma e outra iniciaria o alfabetizado no códigos da comunicação escrita), cálculo aritmético, além de noções de cultura e natureza e de experiência humana e experiência profissional exigiu que Paulo Freire experenciasse o Projeto de Educação de Adultos ensaiado por cinco anos em Recife (Pernambuco), por meio do Serviço de Extensão Cultural da Universidade Federal de Pernambuco com suas instituições básicas de educação e cultura popular: o Círculo de Cultura e o Centro de Cultura. Por ser assim,

[...] em lugar de escola, que nos parece um conceito, entre nós, demasiado carregado de passividade, em face de nossa própria formação (mesmo quando lhe dá o atributo de ativa), contradizendo a dinâmica fase de transição, lançamos o Círculo da Cultura. Em lugar do professor, com tradições fortemente 'doadora', o Coordenador de Debates. Em lugar de aula discursiva, o diálogo. Em lugar de aluno, com tradições passivas, o participante do grupo. Em lugar dos 'pontos' e de programas alienados, programação 
compacta, 'reduzida' e 'codificada' em unidades de aprendizado. (Freire, 1980, p. 103, grifos do autor).

Especialmente nos Círculos de Cultura - unidade de ensino que substituía a "escola" - instituía-se o debate dialógico e grupal - pelas explicações de Freire (1980, p. 154) - "[...] ora em busca do aclaramento de situações, ora em busca de ação mesma, decorrente do aclaramento das situações." Para conferir aclaramento de suas teorizações e da práxis educacional de modo particular no universo vocabular e existencial, palavra geradora (separada em sílaba) e representação gráfica - Paulo Freire descreve uma situação de aprendizagem expressada pela linguagem escrita e falada na Experiência de " 40 horas" de Angicos.

Num dos Círculos de Cultura da Experiência de Angicos - Rio Grande do Norte - que fora coordenado por uma de nossas filhas, Madalena, no quinto dia de debate, em que apenas se fixavam fonemas simples, um dos participantes [alunos] foi ao quadro negro para escrever, uma 'palavra de pensamento. E redigiu: 'o povo vai resouver (corruptela de resolver) os poblemas (corruptela de problemas) do Brasil votando conciente' sem o s da sílaba cons. (Freire, 1980, p. 119, grifos do autor)

A educação de adultos de "método" dialogal e ativo na Experiência de " 40 horas" de Angicos foi firmemente sistematizado numa ideia pedagógica muito esclarecedora de povo se alfabetizando: o povo se alfabetizando para que se conscientize para que se alfabetize. Daí, para Paulo Freire (1980, p. 120), à medida que a educação de adultos de "método" dialogal e ativo "[...] ajude o homem a se conscientizar em torno de sua problemática, em torno de sua condição de pessoa, por isso de sujeito, se instrumentalizará para as suas opções." Daí, a educação de adultos de "método" dialogal e 
ativo em bases populares na Experiência de "40 horas" de Angicos, por conseguinte, dialogou, pois, com a ideia de democratização da cultura - dimensão da democratização fundamental.

\section{Conclusão}

Especialmente, as ideias pedagógicas de Paulo Freire (1980, p. 44) orientavam-se pelo senso de julgamento de que uma "[...] época histórica representa, assim, uma série de aspirações, de anseios, de valores, em busca de plenificação." Essas aspirações de anseios e de valores em busca de plenificação demandaram, consequentemente, projetos de educação adulto igualitário para povo, para dialogar com ele pelo seu testemunho de vida e por educação ativa. Para uma sociedade democrática - pelas reflexões de Paulo Freire (1980, p. 104) havia-se de promover uma educação alfabetizadora (que não levasse o povo a posições quietistas e de paciente), mas que "[...] desenvolvesse a impaciência, a vivacidade, características dos estados de procura, de invenção e reivindicação." Uma educação como esforço de libertação humana com sua indispensável organização reflexiva do pensamento humano.

As ideias pedagógicas de Paulo Freire (1980a, p. 74, grifos nossos) dialogaram, criticamente, com certas ideias pedagógicas, mais precisamente aquelas que qualificavam o povo analfabeto como "enfermo", "paciente" a quem se aplicam "remédios". O povo analfabeto "[...] como uma pessoa que existe à margem da sociedade [...] como uma espécie de 'homem doente', para o qual a alfabetização seria medicamento 'curativo', que lhe permitiria 'voltar' à estrutura 'sadia' da qual havia sido separado." No limite, haveria um repertório de ideias pedagógicas transmitida subliminarmente para o povo para que assim se julgasse. 
Paulo Freire rejeitava, decisivamente, uma educação alfabetizadora de jovens adultos que ditava ideias (em lugar de trocar ideias), uma educação em que o povo fosse "paciente" da alfabetização (mas o seu sujeito), para que o homem do povo,

Não [fosse] esse paciente do processo, cuja virtude única é ter mesmo paciência para suportar o abismo entre sua experiência existencial e o conteúdo que lhe oferecem para sua aprendizagem, mas o seu sujeito. Na verdade, somente com muita paciência é possível tolerar, após as durezas de um dia de trabalho ou de um dia sem 'trabalho' lições que falam de ASA - 'Pedro viu a Asa'. 'A Asa é da Ave'. Lições que falam de Evas e de uvas a homens que as vezes conhecem poucas Evas e nunca comeram uvas. 'Eva viu a uva'. (Freire, 1980, p. 104).

Na Experiência das "40 horas" de Angicos daquele ano de 1963, o discurso do alfabetizando Antônio Ferreira perante o Presidente da República, o governador do Estado, os seus professores e professoras e todos os colegas, singulariza, firmemente, aquela ideia pedagógica de Paulo Freire de povo se alfabetizando: o povo se alfabetizando para que se conscientize, para que se alfabetize.

Em outra hora, há poucos dias, ninguém sabia ler, não sabia de letras algumas, como eu era um que não sabia; [...] $\mathrm{E}$ hoje em dia, graças a Deus e os meus professores, já assino o meu nome e leio algumas coisas, graças a Deus. Tanto que fiquei bastante satisfeito com o alfabetismo que fez a nós aprendermos. Eu, já com a idade avançada, com 51 anos, mas graças a Deus tenho a inteligência e já vou escrevendo qualquer coisa. Hoje mesmo, já fiz uma cartinha pra o Sr. Presidente da República, dizendo algumas coisas. E do mais que peço a sua majestade que é a pessoa maior que nos enxergamos no Brasil, é o Presidente da 
República, quarqué coisa, ouviu, peço que continue o curso de aula para nós todos, não tão somente no Rio Grande do Norte como em todos os lugares por aí que tem necessidade, de milhares e milhares que não sabem as primeiras letras do alfabeto; são pessoas que têm necessidade, para melhorar a situação do Brasil [...]. Tanto que eu fiquei muito satisfeito e mais satisfeito ficarei continuando, a escola. [...] Temos muita necessidade das coisas que nós não sabia, e que hoje estamos sabendo. Em outra bora nós era massa, hoje já não somos massa, estamos sendo povo. Nós todos, alunos, uns 300 e tantos ou 400, já sabemos escrever qualquer coisa, e lê outras coisas. Com a continuação, amanhã ou depois, sabemos escrever as cartinhas do Presidente da República, sabemos fazer qualquer coisa em favor do Brasil, em favor do Estado. Tanto que estamos bastante satisfeitos com estas aulas e devemos continuar. Aqui eu faço pausa. Está me faltando uma música; e desculpe a todos agradecido, ouviu?. (Discurso do alfabetizando Antônio Ferreira, 1963, In Gadotti, 2014, p. 41-42, grifos nossos).

Em Angicos, os jovens e adultos alfabetizados, nos Círculos de Cultura, pelo "Método Paulo Freire" haviam se politizado: "Em outra hora nós era massa, hoje já não somos massa, estamos sendo povo."

\section{Referências bibliográficas}

Brasil. (1950). Relatório das atividades no exercício de 1949, apresentado ao Senhor Ministro da Educação e Saúde, professor Clemente Mariani, pelo Diretor Geral do Departamento Nacional de Educação, professor M. B. Lourenço Filho. In: Serviço de Educação de Adultos no exercício de 1949. Rio de Janeiro. (texto datilografado).

Brasil. (1962). Censo demográfico de 1960. Rio Grande do Norte e Paraíba. Rio de Janeiro: Fundação Instituto Brasileiro de Geografia e Estatística / Departamento de Estatísticas de População. (v. 1, tomo V). 
Brasil, Ministério da Educação e Saúde (1951). Relatório apresentado ao Senhor Ministro da Educação e Saúde, professor Pedro Calmon, pelo Diretor Geral do Departamento Nacional de Educação, professor M. B. Lourenço Filho. In: Serviço de Educação de Adultos no exercício de 1950. Rio de Janeiro. (texto datilografado).

Decreto-Lei n. ${ }^{\circ} 38.968$, de 27 de outubro de 1952. Reforça o princípio da obrigatoriedade do ensino primário elementar, reorganiza a assistência escolar, cria os cursos de educação de adultos e promove uma campanha nacional contra o analfabetismo. Diário do Governo, Lisboa, n. 241, p. 1091. (Suplemento).

Decreto-Lei n. ${ }^{\circ} 38.969$, de 27 de outubro de 1952. Regula a execução do Decreto-Lei n. ${ }^{\circ} 38.968$, que reforça o princípio da obrigatoriedade do ensino primário elementar. Diário do Governo, Lisboa, n. 241, p. 1091.

Fernandes, C. \& Terra, A. (1994). 40 horas de esperança. O método Paulo Freire: política e pedagogia na experiência de Angicos. São Paulo: Editora Ática.

Ferreira, A. G. \& Mota, L. (2011). Representações no plano de educação popular e da Campanha Nacional de Educação de Adultos no ensino normal primário de Coimbra. In: L. Alcoforado, J. A. G. Ferreira, \& A. G. Ferreira, \& C. Vieira et al. (Org.), Educação e formação de adultos. Políticas, práticas e investigação. Coimbra: Imprensa da Universidade de Coimbra.

Freire, P. (1980). Educação como prática da liberdade (11. ${ }^{\mathrm{a}}$ ed.). Rio de Janeiro: Paz e Terra.

Freire, P. (1980a). Conscientização. Teoria e prática da libertação: uma introdução ao pensamento de Paulo Freire (3. ${ }^{a}$ ed.). São Paulo: Editora Moraes.

Gadotti, M. (Org.) (2014). Alfabetizar e conscientizar: Paulo Freire, 50 anos de Angicos. São Paulo: Instituto Paulo Freire.

Gandini, R. P. C. \& Riscal, S. A. (2002). Manuel Bergström Lourenço Filho. In: M. L. A. Fávero \& J. M. Britto (Org.), Dicionário de educadores no Brasil. Da colônia aos dias atuais (2. ${ }^{\mathrm{a}}$ ed.) aum. Rio de Janeiro: Editora UFRJ-Mec-Inep-Comped.

Lourenço Filho, M. B. (1945). O problema da educação de adultos. Revista Brasileira de Estudos Pedagógicos, Rio de Janeiro, 5(14), 169-185.

Lourenço Filho, M. B. (1949). Educação de base para adolescentes e adultos. Revista Brasileira de Estudos Pedagógicos, 13(37), 122-140.

Lourenço Filho, M. B. (2002 [1940]). Prefácio da $1^{\text {a }}$ edição. In: R. Lourenço Filho \& C. Monarcha (Org.), Tendências da educação brasileira (2. ${ }^{a}$ ed.). Brasília: Instituto Nacional de Estudos e Pesquisas Educacionais Anísio Teixeira.

Serviço Gráfico do Instituto Brasileiro de Geografia e Estatística (1947). Declarações do Sr. Ministro da Educação e Saúde, professor Clemente Mariani, em entrevista coletiva à imprensa, em 15 de janeiro de 1947. In: Documentos iniciais da Campanha. Rio de Janeiro: Serviço Gráfico do Instituto Brasileiro de Geografia e Estatística. 